\title{
Microbiological investigation of Escherichia coli isolates from cloacal and feacal swabs of broiler chickens for extended spectrum beta lactamase (ESBL) enzymes
}

\author{
Eze Emmanuel ${ }^{1}$, Nwakeze Emmanuel ${ }^{1}$, Oji Anthonia ${ }^{1}$, Ejikeugwu Chika ${ }^{2}$, Iroha \\ Ifeanyichukwu ${ }^{1}$ \\ ${ }^{I}$ (Department of Applied Microbiology, Ebonyi State University, P.M.B 053, Abakaliki, Nigeria) \\ ${ }_{2}^{2}$ (Department of Pharmaceutical Microbiology and Biotechnology, Nnamdi Azikiwe University, P.M.B 5025, \\ Awka, Nigeria)
}

\begin{abstract}
Extended spectrum beta-lactamases (ESBLs) are enzymes that hydrolyze oxyimino cephalosporins (except cephamycins) and monobactams but are inhibited by clavulanic acid. Pathogenic bacteria producing ESBL exhibit co-resistance to many other classes of antibiotics, and this result in limitation of therapeutic option in both veterinary and human medicine. This research work demonstrated ESBL production from Escherichia coli isolates of poultry origin in Abakaliki, Ebonyi State, Nigeria. A total of 200 feacal and cloacal swab samples from broiler chickens were analyzed in this study. Swab samples were cultured and incubated at $37^{\circ} \mathrm{C}$ for 18-24 hrs, and colonies growing on agar plates were identified by standard microbiology techniques. Antibiogram was conducted on all isolates by Kirby-Bauer disk diffusion method and ESBL production was evaluated as per the double disk synergy test (DDST) method. ESBL production was detected in 16 E. coli isolates from feacal swab samples and 20 E. coli isolates from cloacal swab samples. All isolates showed high resistance to ceftazidime, cefotaxime, sulphamethoxazole-trimethoprim, ampicillin, gentamicin, ciprofloxacin, tetracycline and ofloxacin. The frequency of ESBL production in E. coli isolates from broiler chickens in this study has clinical implications for the treatment of bacterial related diseases in human population, thus the need to control the use of antibiotics for non-human purposes in this environment.
\end{abstract}

Keywords: ESBL, Antibiotic Resistance, Poultry, Feacal Samples, Nigeria

Corresponding author: ejikeugwu_chika@yahoo.com, +2348097684562

\section{INTRODUCTION}

The production of $\beta$-lactamase enzymes (which makes $\beta$-lactam drugs inefficacious) by pathogenic bacteria is the mainstay behind the rising level of resistance in the health sector [1]. Antibiotic resistance is a global phenomenon which has flawed chemotherapeutic measures in our hospitals for the reason that it makes drugs that were once effective to be less efficacious in the treatment of some bacterial related diseases. The emergence of multidrug resistance strains of microbes including those that produce extended spectrum $\beta$ lactamase (ESBL) enzymes has greatly contributed to this therapeutic menace in both the community and hospital settings. ESBLs are $\beta$-lactamase enzymes that have the exceptional ability to breakdown $3^{\text {rd }}$-generation oxyimino cephalosporins and monobactams but are susceptible to cephamycins and carbapenems $[2,3,4]$. Pathogenic bacteria (including Escherichia coli) that produce ESBL show resistance to a wide variety of $\beta$ lactams and some non- $\beta$-lactam drugs including fluoroquinolones, aminoglycosides and sulphamethoxazoles [5]. Failure to the therapeutic effectiveness of cephalosporins in clinical medicine has been attributed to ESBLproducing microorganisms [6]; and organisms producing these all important enzymes (ESBL) have been reported in both community and clinical environments. Escherichia coli are a widely studied bacterium and harmless microorganism that thrive in the gut of animals (humans and poultry birds inclusive). Some strains of $E$. coli can cause bacterial related resistant infections and serious food poisoning in humans; and are occasionally responsible for product recalls due to food contamination in the food industry [7]. Studies have shown that Enterobacteriaceae (including E. coli) from poultry origin produce ESBL enzymes and; these are responsible for zoonotic infections in humans [7,8,9]. In Nigeria (Abakaliki, Ebonyi State precisely), these enzymes have been reported in E. coli from animal and human origin [10]. Bearing in mind the clinical significance of community organisms producing ESBLs, this research work investigated the occurrence of ESBLs from feacal and cloacal swabs of poultry birds in Abakaliki metropolis, Ebonyi State, Nigeria.

II.

MATERIALS AND METHODS

Collection of samples: A total of 200 samples comprising of 100 fecal swabs and 100 cloacal swabs were collected from poultry birds (broiler chickens) in Abakaliki metropolis, Ebonyi State, Nigeria. All samples were cultured primarily in nutrient broth at $37^{\circ} \mathrm{C}$ for $18-24 \mathrm{hrs}$, and subcultured onto MacConkey, brilliant green and 
Eosin Methylene Blue (EMB) agar. Colonies showing characteristic morphology of E. coli were repeatedly subcultured onto EMB agar and MacConkey agar to obtain pure culture, and these were biochemically identified based on standard microbiology techniques after subculturing onto nutrient agar [11].

ESBL screening: Isolated $E$. coli were screened for the production of ESBL using a modified disc diffusion method by subjecting them to in vitro antimicrobial susceptibility studies using cefotaxime (30 $\mu \mathrm{g})$, ceftazidime $(30 \mu \mathrm{g})$, aztreonam $(30 \mu \mathrm{g})$, cefoxitin $(30 \mu \mathrm{g})$, cefuroxime $(30 \mu \mathrm{g})$ and ampicillin $(30 \mu \mathrm{g})$. E. coli isolates that were resistant to any of the tested antibiotics according to the screening breakpoints of the Clinical Laboratory Standard Institute (CLSI) criteria were further subjected to double disc synergy test to confirm ESBL production [12].

Double disc synergy test (DDST): ESBL production was detected in suspected isolates by the DDST method. DDST was performed by placing a combination disc of amoxicillin/clavulanic acid $(20 / 10 \mu \mathrm{g})$ on the center of a Mueller-Hinton agar plate previously inoculated with the test organism (adjusted to $0.5 \mathrm{McF}$ arland turbidity standards). Cefotaxime $(30 \mu \mathrm{g})$ and ceftazidime $(30 \mu \mathrm{g})$ disks were each placed $15 \mathrm{~mm}$ apart from the central disk, and the plate(s) incubated at $37^{\circ} \mathrm{C}$ for $18-24 \mathrm{hrs}$. A difference of $\geq 5 \mathrm{~mm}$ in the diameter of the inhibition zone between ceftazidime or cefotaxime disk and the central disk (amoxicillin/clavulanic acid) was considered positive for ESBL production $[2,4]$.

Antimicrobial resistance studies: Antibiogram was performed by Kirby-Bauer disk diffusion method as per the CLSI guidelines (CLSI, 2008). The following antibiotic disks (procured from Oxoid, UK) were used for susceptibility studies: ciprofloxacin $(10 \mu \mathrm{g})$, ofloxacin $(10 \mu \mathrm{g})$, cefotaxime $(30 \mu \mathrm{g})$, ceftazidime $(30 \mu \mathrm{g})$, ampicillin $(10 \mu \mathrm{g})$, gentamicin $(15 \mu \mathrm{g})$, sulphamethoxazole/trimethoprim $(25 \mu \mathrm{g})$, and tetracycline $(10 \mu \mathrm{g})$.

\section{RESULTS}

During the study period, 200 feacal and cloacal swab samples from broiler chickens in Abakaliki metropolis, Ebonyi State of Nigeria were recruited and investigated for Escherichia coli producing ESBL enzymes. The feacal and cloacal swab samples used in this study were cultured on selective culture media (comprising of MacConkey, brilliant green and EMB agar) and subcultured for the isolation of pure cultures of Escherichia coli. All isolated E. coli isolates were confirmed as Gram negative, and these were confirmed biochemically using indole test, carbohydrate fermentation test, and triple sugar iron (TSI) agar. The results of the isolation of E. coli isolates are shown in Table 1 . In all, feacal swab samples $(\mathrm{n}=100)$ produced 67 E. coli isolates while cloacal swab samples $(\mathrm{n}=100)$ produced $74 \mathrm{E}$. coli isolates. Table 2 shows the frequency of ESBL production from the various poultry samples used in this study. ESBL production was observed more in cloacal swab samples compared to the feacal samples in our study. Overall, $36 \mathrm{E}$. coli isolates produced ESBL enzymes out of the 141 isolates of $E$. coli employed for this study. The antimicrobial resistance pattern of our ESBLproducing E. coli isolates is shown in Table 3. The resistance rates of the E. coli isolates to ciprofloxacin, ofloxacin, cefotaxime and ceftazidime were $77.8 \%, 69.4 \%, 97.2 \%$ and $91.7 \%$. This was followed by gentamicin, tetracycline, and sulphamethoxazole-trimethoprim whose percentage resistances were $80.6 \%$, $55.6 \%$ and $94.4 \%$. All the test isolates were completely resistant to ampicillin (100\%).

\section{TABLES}

Table 1. Frequency of Escherichia coli from the swab samples

\begin{tabular}{cc}
\hline Samples (n) & Number of isolates \\
\hline Feacal (100) & 67 \\
Cloacal (100) & 74 \\
\hline Total & $\mathbf{1 4 1}$
\end{tabular}

Table 2. Frequency of ESBL production

\begin{tabular}{ccc}
\hline $\begin{array}{c}\text { Number of isolates } \\
\text { from samples }\end{array}$ & $\begin{array}{c}\text { Number of isolates positive } \\
\text { for ESBL }\end{array}$ & $\begin{array}{c}\text { Number of isolates negative } \\
\text { for ESBL }\end{array}$ \\
\hline Feacal $(\mathrm{n}=67)$ & 16 & 51 \\
Cloacal $(\mathrm{n}=74)$ & 20 & 54 \\
\hline Total & $\mathbf{3 6}$ & $\mathbf{1 0 5}$ \\
\hline
\end{tabular}

Table 3. Resistance profile of ESBL positive $E$. coli isolates

\begin{tabular}{cc}
\hline Antibiotics $(\boldsymbol{\mu g})$ & No (\%) of ESBL Production (n=36) \\
\hline Ciprofloxacin (10) & $28(77.8)$ \\
Ofloxacin (10) & $25(69.4)$ \\
Cefotaxime (30) & $35(97.2)$ \\
\hline
\end{tabular}




\begin{tabular}{cc}
\hline Ceftazidime (30) & $33(91.7)$ \\
Ampicillin (10) & $36(100)$ \\
Gentamicin (15) & $29(80.6)$ \\
Tetracycline (10) & $20(55.6)$ \\
Sulphamethoxazole-trimethoprim (25) & $36(100)$ \\
\hline
\end{tabular}

\section{DISCUSSION}

Gram negative organisms (including Escherichia coli) producing extended spectrum $\beta$-lactamase (ESBL) enzymes has been reported in both the community and hospital environment, and they are a serious source of concern to clinicians and microbiologists because they contribute to most treatment failures when cephalosporins and like drugs are used for treating bacterial related infections. The emergence and spread of ESBL organisms in the community constitutes a serious threat to the effective management and treatment of bacterial related infectious diseases and this compromises the efficacy of some available conventional antibiotics. Resistance to $\beta$-lactam antibiotics in $E$. coli is usually caused by ESBL enzymes amongst other $\beta$ lactamases, and this enzyme has the ability to breakdown and renders inefficacious a wide variety of antibiotics (especially the $\beta$-lactams) when used for treatment $[4,5,8]$. In this study, we evaluated the occurrence of ESBL enzymes from E. coli isolates of poultry origin. Two hundred (200) feacal and cloacal swab samples of poultry origin from Abakaliki metropolis, Ebonyi State of Nigeria was recruited and a total of 141 E. coli isolates was recovered from the samples (Table 1). A total of 16 E. coli isolates from feacal swab samples produced ESBL while 20 E. coli isolates from cloacal swab samples produced ESBL enzymes. This data as obtained in our study raises concern about the occurrence of ESBL in the community, especially from poultry origin which serves as a source of meat for humans. It is obvious from our study that ESBL-producing E. coli occur frequently in broiler chickens, and these can serve as reservoirs through which resistance genes (including ESBLs) can be transferred to human bacteria, and this will in turn cause infection in human population. The frequency of ESBL production in E. coli isolates of poultry origin (as obtained in our study) has also been reported in other quarters $[8,9,10]$. The resistance profile of all ESBL-producing $E$. coli isolates are shown in Table 3. The ESBL-producing E. coli isolates showed varying rates of resistance to the tested antibiotics. From our study (Table 3), the resistance rates of the ESBL positive E. coli isolates to tested antibiotics was high, and this shows the multidrug resistance nature of microorganisms that produce this all important enzymes (ESBLs). Growing resistance rates of pathogenic microorganisms (including E. coli that produce ESBL enzymes) have been previously reported $[13,14,15,16]$, and there is therefore need to begin to reverse this trend in order to preserve available drugs and ensure better treatment prognosis for patients infected by these organisms. The ESBL-producing $E$. coli isolates of poultry origin in our study was highly resistant to common antibiotics used for the treatment of bacterial related infections. High resistance rates of ESBL-producing $E$. coli isolates as obtained in our study (Table 3) have also been reported previously [7,10,17]. The practice of using antibiotics (especially those meant for human purposes) in compounding livestock feeds, for poultry production and for other veterinary purposes including animal husbandry could be the likely cause for the growing prevalence of resistance strains of microorganisms (including those that produce ESBL enzymes) from the community. A recent study in Southeast Nigeria (Owerri in particular) also reported high resistance rates of ESBL-producing $E$. coli isolates from poultry origin to some available conventional drugs including sulphamethoxazoletrimethoprim, ampicillin, cefotaxime, ceftazidime, ticarcillin, ceftriaxone, and nalidixic acid [18]. The results of ESBL production amongst $E$. coli isolates of poultry origin and subsequent resistance of these organisms to some available conventional drugs (as obtainable in our study) is worrisome and calls for concerted national effort (including further molecular studies in particular) to contain the situation. Bacterial organisms producing ESBL enzymes pose a great therapeutic challenge to both clinicians and microbiologists owing to the multidrug resistance nature of such microbes which makes it complicated to prescribe antibiotics, thus limiting treatment options. In addition, ESBL-producing organisms frequently carry antibiotic resistance genes which usually encode resistance to other non- $\beta$-lactams; thus it is of utmost importance to control antibiotic usage in poultry and animal husbandry ventures because they can serve as routes via which resistance strains of microbes are transported to susceptible humans. In conclusion, our study have demonstrated that $E$. coli isolates of poultry origin produce ESBL enzymes, and that these are resistant to some available conventional drugs. There is therefore need for stringent measures to control the use of antibiotics in poultry feeds and livestock production in this environment, a practice that allows for the selection of resistant strains of microorganisms (including those that produce ESBL enzymes). Increased awareness on ESBL-producing E. coli isolates in both the community and hospital settings and improved testing methodology incorporating molecular studies for this all important enzymes (ESBLs) is vital to prevent the emergence and spread of ESBL organisms within the community. 


\section{REFERENCES}

[1]. A.M Ahmed and T Shimamoto, Emergence of a cefepime and cefpirome resistant Citrobacter freudii. clinical isolates harboring a novel chromosomally encoded AMPC $\beta$ - lactamase, CMY-37. Int. J. Antimicrob Agents, 32, 2008, 256-261.

[2]. C Ejikeugwu, M Ikegbunam, C Ugwu, P Eze, I Iroha and C.O Esimone, Phenotypic detection of Klebsiella pneumoniae strainsproducing extended spectrum $\beta$-lactamase (ESBL) enzymes. Scholars Academic Journal of Biosciences, 1(1), 2013, $20-23$.

[3]. P.A Bradford, P.J Petersen, I.M Fingerman, D.G White, Characterization of expanded-spectrum cephalosporin resistance in E. coli isolates associated with bovine calf diarrhoeal disease. J Antimicrob Chemother, 44, 1999, 607-610.

[4]. J.D.D Pitout, K.S Thomsons, N.D Hanson, A.F Ehrhardt, $\beta$-lactamase responsible for resistance to expanded spectrum cephalosporin in Klebsiella pneumomiae, Escherichia coli and Proteus mirabilis isolates recovered from South Africa. Antimicrob Agents Chemother, 42, 1998, 1350-1355.

[5]. G.A Jacoby and L.S Munoz-Price, The New Beta-Lactamases. N. Engl. J. Med, 352(4), 2005, 380-391.

[6]. R Melano, A Petroni, A Garuth, H.A Sakea, L Mange, F Pasteran, M Rapport, A Rossi, M Galas, New carbenicillin hydrolyzing $\beta$ lactamase (CARB-T) from Vibro cholerae non-01, non-0139 strains encoded by the VCR region of the $V$. Cholerae genome. Antimicrob Agents Chemother, 46, 2002, 2162-2168.

[7]. R.L Vogt and L Dippold, Escherichia coli O157:H7 outbreak associated with consumption of ground beef. Public Health Rep, 120 (2), 2005, 174-8.

[8]. V Jasson, I Sampers, N Botteldoorn, F Lopez-Galvez, L Baert, S Denayer, A Rajkovic, I Habib, L De Zutter, J Debevere and M Uyttendaele, Characterization of Escherichia coli from raw poultry in Belgium and impact on the detection of Campylobacter jejuni using Bolton broth. International Journal of Food Microbiology, 135, 2009, 248-253.

[9]. K.F Chah and N.E Nweze, Antibiotic use in poultry production in Nsukka, Southeast Nigeria. Proc. Nig. Soc. Anim. Prod, 26, 2001, 69-72.

[10]. I.R Iroha, E.C Okonkwo, E.A Nwakaeze, E.A Oji, F.N Afiukwa, A.C Nwuzo, T Ayogu, Antimicrobial resistance of Escherichia coli isolated from animal and human clinical sample. Global Research Journal of microbiology, 2(1), 2012, 85-89.

[11]. 11. J Vandepitte, J Verhaegen, K Engbaek, P Rohner, P Piot, and C.C Heuck, Bacteriological investigations. In: World health Organization $\left(2^{\text {nd }}\right.$ ed.), Basic Laboratory Procedures in Clinical Bacteriology, WHO, Geneva, 2003.

[12]. Clinical Laboratory Standard Institute (CLSI), Performance standards for antimicrobial disk and dilution susceptibility test for bacteria isolated from animals. Approved Standard M31-A3. $3^{\text {rd }}$ ed. Wayne, PA: Clinical Laboratory Standards Institutes. 2008.

[13]. K Yamaguchi, D Mathai, D.J Biedenbach, M.T Lewis, A.C Gales, R.N Jones, Evaluation of the in vitro activity of six broadspectrum beta-lactam antimicrobial agents tested against over 2,000 clinical isolates from 22 medical centers in Japan. Japan Antimicrobial resistance study Group. Diag. Microbiol. Infect. Dis. 34, 1999, 123-134.

[14]. N Woodford, P.M Tierno, K Young Jr, L Tysall, M.F Palepou, E Ward, E.R Painter, D.F Suber, D Shungu, L.L Silver, K Inglima, Kornblum, D.M Livermore, Outbreak of Klebsiella pneumoniae producing a new carbapenem-hydrolyzing class a beta-lactamase, KPC-3, in a New York Medical center. Antimicrob. Agents Chemother. 48, 2004, 4793-4799.

[15]. Z Xiong, D Zhu, F Wamg, Y Zhang, R Okamoto, M Inove, Investigation of extended-spectrum beta-lactamase in Klebsiellae pneumoniae and Escherichia coli from China. Dign Microbiol Infect Dis 44, 2002, 195-200.

[16]. A.E Van den Bogaard, N London, C Driessen, E.E Stobberingh, Antibiotic resistance of fecal Escherichia coli in poultry, poultry farms and poultry slaughters. J Antimicrobio Chemother. 44, 2001, 763-771.

[17]. R.S Sayah, J.B Kaneene, and M.R Johnson, Pattern of antimicrobial resistance observed in Escherichia coli isolates obtained from domestic and wild animal fecal samples, human sewage and surface water. Appl. Environ. Microbiol, 71, $2005,1394-1404$.

[18]. C Duru, E Nwanegbo, M Adikwu, C Ejikeugwu and C Esimone. Extended-Spectrum Beta- Lactamase-Producing Escherichia Coli Strains of Poultry Origin in Owerri, Nigeria. World Journal of Medical Sciences, 8(4), 2013, 349-354. 